Case Report

\title{
Re-emergence of Posttraumatic Stress Disorder Nightmares With Nursing Home Admission: Treatment With Prazosin
}

\author{
Kim G. Johnson MD, Jules Rosen MD* \\ Department of Psychiatry, University of Pittsburgh School of Medicine, Pittsburgh, PA
}

Keywords:

PTSD

nightmares

prazosin

depression

nursing home

Holocaust

\begin{abstract}
A B S T R A C T
Seniors with a history of emotional trauma decades earlier can experience a recurrence of posttraumatic stress disorder symptoms when transitioning to a nursing home. We present the case of an 86-year-old male Holocaust survivor admitted to a nursing home for physical therapy and rehabilitation 6 weeks after the death of his wife; the patient was expressing a persistent death wish. Despite the multiple risk factors for depression, his distress was specifically related to the reemergence of nightly posttraumatic nightmares. Over the course of 1 week of treatment with $1 \mathrm{mg}$ prazosin at bedtime, his nightmares and his death wish completely resolved. He achieved his rehabilitation goals and was discharged to a community setting. This report highlights the importance of considering posttraumatic stress disorder in nursing home residents with a history of emotional trauma, and understanding how to address these symptoms pharmacologically and nonpharmacologically.
\end{abstract}

Published by Elsevier Inc. on behalf of the American Medical Directors Association, Inc.
Posttraumatic stress disorder (PTSD) symptoms can reemerge even decades later as seniors face challenges associated with aging. ${ }^{1}$ Nursing home placement, although stressful for most seniors, can be particularly trying for survivors of involuntary incarceration, such as concentration camps, prisoner of war camps, or prison. Although these seniors may present with symptoms suggestive of depression, they also can present with symptoms specific to PTSD. ${ }^{2}$ In some cases, this distinction will change the treatment approach.

\section{Case Report}

An 86-year-old male Holocaust survivor was admitted to a nursing facility for physical therapy after a humerus fracture sustained in a fall. His wife of 60 years had died after a long illness 6 weeks earlier. At the nursing home, he verbalized to the nursing staff on several occasions that he had "nothing to live for." The primary care physician in the nursing facility requested psychiatric consultation for evaluation of depression.

The patient's history is significant for PTSD resulting from concentration camp imprisonment from ages 12 to 17. His parents, siblings, and more than 30 other relatives perished. After liberation, he married another survivor and moved to the United States, where he raised 3 children and worked as a plumber. He described vivid nightmares of his concentration camp experiences for several years

The authors declare no conflicts of interest.

* Address correspondence to Jules Rosen, MD, WPIC, 3811 O'Hara St, Pittsburgh, PA 15213.

E-mail address: rosenji@upmc.edu (J. Rosen). after liberation, but over time, these became infrequent, occurring no more than once or twice per year.

According to the patient's community primary care physician, he was "adjusting to his wife's death well," and his mood was good before his fall. He continued taking $50 \mathrm{mg}$ sertraline daily, which had been initiated by his primary care physician during his wife's illness.

Arriving at the nursing facility, the patient voiced renewed distress over his wife's death, reporting feelings of hopelessness and helplessness, passive death wish, and severe sleep disturbance. Despite these complaints, he was progressing well in physical therapy and engaged socially with staff in the facility.

Based on a comprehensive evaluation, the psychiatric team concluded that the patient was continuing to grieve for his wife with appropriate emotional distress, and he was not experiencing a major depression. In fact, his progress in physical therapy and social engagement within the nursing home environment were not suggestive of depression. However, he was experiencing a recurrence of posttraumatic nightmares. On admission to the nursing facility, eidetic nightmares of his concentration camp experiences recurred nightly. According to the patient, overwhelming daytime apprehension of reliving the traumatic images each night resulted in his death wish. Based on this evaluation, the treatment plan focused exclusively on his nightmares. The patient was started on a $1 \mathrm{mg}$ dose of prazosin at bedtime, with monitoring of blood pressure. Nonpharmacologic approaches included leaving lights on at night, reassuring the patient that the nightmares would disappear, and educating the nursing staff as to how to respond to him at night when he is terrified.

After 3 nights, the patient reported a decrease in the frequency and intensity of his nightmares. After 1 week on prazosin, his 
nightmares completely disappeared, and his daytime symptoms of anxiety and despair resolved. He successfully completed physical therapy and was discharged from the nursing home.

\section{Discussion}

The transition from the community to an institutional setting is stressful for most seniors, ${ }^{3}$ and victims of trauma with past PTSD are especially vulnerable and can experience a reemergence of symptoms. ${ }^{4}$ Former prisoners of war or Holocaust survivors, even if doing well in the community, can experience recurrent symptoms when confined to an institutional setting. For this reason, obtaining a history of early life trauma on admission to a nursing home can help to inform both pharmacologic and nonpharmacologic approaches.

Selective serotonin reuptake inhibitors (SSRIs) are the pharmacologic treatment of choice for patients with PTSD. ${ }^{5}$ However, patients who are taking an SSRI for PTSD can still have residual or recurring nightmares and sleep disturbance. The patient was taking an SSRI on admission but suffered from re-emergent nightmares.

Nightmares associated with PTSD are typically described as "videotape replays," or eidetic. These dreams are so distressing that survivors dread going to sleep, fearing that they will find themselves back in the traumatic situation each night. Posttraumatic dreams are associated with a constellation of psychopathologic developments, including symptoms of depression and anxiety. ${ }^{6}$

Low-dose prazosin is the recommended treatment for PTSDrelated nightmares, ${ }^{7}$ even for patients taking SSRIs and other psychotropic medications. ${ }^{8,9}$ Although low-dose prazosin is well tolerated in the geriatric population, even among those with other medical conditions and taking other blood pressure medications, there are some safety concerns. A common adverse effect of prazosin is orthostatic hypotension, especially after the first dose administration. ${ }^{10}$ Therefore, blood pressure should be monitored during initial doses.

A study of prazosin use in an older population of male war veterans and Holocaust survivors in a community nursing home supports our patient's experience. Low doses of prazosin were effective in treating nightmares and sleep disturbance without significant hypotensive effects in this vulnerable population. ${ }^{11}$ Although the optimal dose of prazosin has not yet been established for nightmares, several studies initiated treatment with $1 \mathrm{mg}$ and titrated the dose until desired effects were achieved, up to $20 \mathrm{mg}$. ${ }^{12}$ However, a favorable response was reported within several days in $60 \%$ of patients on a dosage of $1 \mathrm{mg}$ daily. ${ }^{13}$

Once the patient's nightmares resolved, his daytime thoughts of dying, helplessness, and hopelessness also subsided. This is consistent with studies of prazosin's effect on nightmares noting improvement in daytime symptoms in all 3 PTSD symptom clusters including reexperiencing/intrusion, avoidance/numbing, and hyperarousal. ${ }^{14-17}$ However, more studies are needed to determine whether this is a primary pharmacologic effect or secondary to improved sleep at night. $^{18}$

This report highlights the importance of obtaining a history of traumatic exposure in nursing home residents. Although the patient's presentation was suggestive of depression or complicated grief reaction, the primary problem was nightmares due to recurrent PTSD. Targeting the nightmares with evidence-based pharmacotherapy, nonpharmacologic approaches, and nursing staff education resulted in complete resolution of all of the patient's symptoms. It is important to consider the enduring impact of prior emotional trauma or abuse among patients transitioning into nursing home settings.

\section{References}

1. Rintamaki LS, Weaver FM, Elbaum PL, et al. Persistence of traumatic memories in World War II prisoners of war. J Am Geriatr Soc 2009;57:2257-2262.

2. Rosen J. The persistence of traumatic memories in World War II prisoners of war. J Am Geriatr Soc 2009;57:2346-2347.

3. Nypaver JM, Titus M, Brugler CJ. Patient transfer to rehabilitation: Just another move? Rehabil Nurs 1996;2:94-97.

4. Anderson KA, Fields NL, Dobb LA. Understanding the impact of early-life trauma in nursing home residents. J Gerontol Soc Work 2011;54:755-767.

5. Forbes D, Creamer M, Bisson JI, et al. A guide to guidelines for the treatment of PTSD and related conditions. J Trauma Stress 2010;23:537-552.

6. Wittmann L, Schredl M, Kramer M. Dreaming in posttraumatic stress disorder: A critical review of phenomenology, psychophysiology and treatment. Psychother Psychosom 2007;76:25-39.

7. Aurora RN, Zak RS, Auerbach SH, et al. Best practice guide for the treatment of nightmare disorder in adults. J Clin Sleep Med 2010;6:389-401.

8. Taylor FB, Martin P, Thompson C, et al. Prazosin effects on objective sleep measures and clinical symptoms in civilian trauma posttraumatic stress disorder: A placebo-controlled study. Biol Psychiatry 2008;63:629-632.

9. Raskind MA, Peskind ER, Hoff DJ, et al. A parallel group placebo controlled study of prazosin for trauma nightmares and sleep disturbance in combat veterans with post-traumatic stress disorder. Biol Psychiatry 2007;61: 928-934.

10. Meredith PA. Is postural hypotension a real problem with antihypertensive medication? Cardiology 2001;96:19-24.

11. Peskind ER, Bonner LT, Hoff DJ, Raskind MA. Prazosin reduces trauma-related nightmares in older men with chronic posttraumatic stress disorder. J Geriatr Psychiatry Neurol 2003;16:165-171.

12. Miller LJ. Prazosin for the treatment of posttraumatic stress disorder sleep disturbances. Pharmacotherapy 2008;28:656-666.

13. Taylor F, Raskind MA. The alpha1-adrenergic antagonist prazosin improves sleep and nightmares in civilian trauma posttraumatic stress disorder. J Clin Psychopharmacol 2002;22:82-85.

14. Raskind MA, Peskind ER, Kanter ED, et al. Reduction of nightmares and other PTSD symptoms in combat veterans by prazosin: A placebo-controlled study. Am J Psychiatry 2003;160:371-373.

15. Germain A, Richardson R, Moul DE, et al. Placebo-controlled comparison of prazosin and cognitive-behavioral treatments for sleep disturbances in US military veterans. J Psychosom Res 2012;72:89-96.

16. Thompson CE, Taylor FB, McFall MF, et al. Nonnightmare distressed awakenings in veterans with posttraumatic stress disorder: Response to prazosin. J Traumatic Stress 2008;21:417-420.

17. Taylor FB, Lowe K, Thompson $\mathrm{C}$, et al. Daytime prazosin reduces psychological distress to trauma specific cues in civilian trauma posttraumatic stress disorder. Biol Psychiatry 2006;59:577-581.

18. Raskind MA, Peskind ER, Hoff DJ, et al. A parallel group placebo controlled study of prazosin for trauma nightmares and sleep disturbance in combat veterans with post-traumatic stress disorder. Biol Psychiatry 2007;61: 928-934. 